\title{
Análise da Competitividade Internacional do Agronegócio Brasileiro no período de 2003 a 2013
}

\author{
http://dx.doi.org/10.21527/2237-6453.2019.49.59-78
}

Recebido em: 2/9/2017

Aceito em: $11 / 6 / 2019$

Codjo Olivier Sossa, ${ }^{1}$ Leandro Batista Duarte ${ }^{2}$

\begin{abstract}
RESUMO
Esta pesquisa busca analisar se o Brasil continua a apresentar vantagem comparativa e competitividade no comércio internacional do agronegócio no período de 2003 a 2013. Para isso foram analisadas as commodities negociadas na BM\&F e as exportações aos Blocos Comerciais. Os dados foram calculados a partir dos diversos indicadores de comércio internacional do país, como os índices de Vantagem Comparativa Revelada (VCR), Vantagem Comparativa Revelada Simétrica (VCRS), Vantagem Relativa na Exportação (VRE) e Competitividade Revelada (CR). Também com o intuito de analisar o padrão de especialização por meio da vantagem comparativa foram calculados o Indicador de Contribuição ao Saldo Comercial (ICSC), o Índice de Concentração por Produtos das Exportações (ICP) e a Taxa de Cobertura (TC). Nos resultados, observou-se que o Brasil possui vantagem na exportação de praticamente todas as commodities analisadas, como o café, açúcar, carne de bovina e soja e que suas competitividades estão em alta no comércio internacional. Em relação à competitividade no comércio, todos os produtos, exceto o algodão e o milho, proporcionam saldos positivos na balança comercial da commodity.
\end{abstract}

Palavras-chave: Índices de competitividade. Commodities. Exportações. Brasil.

ANALYSIS OF THE INTERNATIONAL COMPETITIVENESS OF BRAZILIAN AGRIBUSINESS IN THE PERIOD 2003 TO 2013 ABSTRACT

This research seeks to analyze whether Brazil continues to have comparative advantage and competitiveness in the international trade of agribusiness, from 2003 to 2013. For this, the commodities traded on BM \& F and exports to the Commercial Blocks were analyzed. The data were calculated from the various indicators of the country's international trade, such as the Revealed Comparative Advantage (VCR), Compared Revealed Advantage (VCRS), Relative Advantage in Exports (VRE) and Revealed Competitiveness (CR) indices. The Trade Balance Contribution Indicator (ICSC), the Export Concentration Index (ICP) and the Coverage Ratio (TC) were also calculated with the aim of analyzing the specialization pattern through comparative advantage. In the results, it was observed that Brazil has an advantage in the export of practically all analyzed commodities, such as coffee, sugar, beef and soybean; and that its competitiveness is high in international trade. In relation to competitiveness in trade, all products, except cotton and corn, provide positive balances in the trade balance of the commodity.

Keywords: Competitiveness indexes. Commodities. Exports. Brazil.

\footnotetext{
${ }^{1}$ Mestre em Economia pela Universidade Federal de Pernambuco (Ufpe). Aluno do Doutorado em Estatística da Universidade Federal de Pernambuco (Ufpe). oliviersossa@gmail.com

${ }^{2}$ Mestre em Economia pela Universidade Federal de Viçosa (UFV). Doutorando em Economia pela Universidade Federal de Pernambuco (Ufpe). Professor do Departamento de Ciências Sociais Aplicadas da Universidade Estadual de Feira de Santana (Uefs). leandro.duarte1@hotmail.com
} 
Na década de 90 houve uma abertura comercial que expôs o Brasil a uma maior competição internacional, levando a rearranjos e significativa modernização do seu processo produtivo, de tal forma que somente as atividades que se tornaram, ou já eram competitivas comercialmente, conseguiram sobreviver no mercado. Então, a lógica da competitividade internacional exige que as unidades de produção avancem em termos tecnológicos, em busca da maximização da eficiência na produção e na competitividade (FREITAS; FOSSATI; NICOLA, 2005).

A abertura comercial ocorre porque as capacidades produtivas das nações são diferentes e é compensatório abrir mão de gerar tudo que o país necessita para então produzir produtos que possuem vantagem comparativa e comercializá-los com outros países, obtendo então os ganhos de comércio. A troca voluntária entre nações é defendida desde a teoria seminal de comércio internacional de David Ricardo, que se apoiava no argumento das vantagens comparativas (PAGANINI; FRAGA, 2014).

Neste contexto, como forma de comercialização, têm-se as commodities, ${ }^{3}$ as quais representaram $65 \%$ do valor das exportações brasileiras, segundo levantamento de 2014 da Conferência das Nações Unidas sobre Comércio e Desenvolvimento (Unctad). As dez primeiras posições no ranking do Ministério da Indústria, Comércio Exterior e Serviços (MDIC..., 2017) de produtos mais exportados são ocupadas por commodities. As exportações brasileiras somaram US\$ 191 bilhões em 2015.

As commodities podem ser vendidas como qualquer mercadoria, mas são normalmente negociadas no mercado futuro, em bolsas de valores, ou seja, o produtor e comprador firmam um contrato com um preço fixado hoje para a entrega e pagamento do produto em uma data futura predefinida. No Brasil, as commodities são negociadas na Bolsa de Valores, Mercadorias e Futuros BM\&F Bovespa. O contrato é formalizado para determinada quantidade de cada produto.

As commodities agropecuárias negociadas na BM\&F são: açúcar, algodão, boi gordo, café, soja e milho. Além desses encontram-se o álcool e o bezerro, mas devido à indisponibilidade destas commodities, não foram analisadas. O mercado agropecuário brasileiro ocupa uma posição de destaque perante o comércio mundial, pois se encontra entre os primeiros exportadores e produtores mundiais de, praticamente, todas as commodities analisadas no presente artigo.

Grande parte dos trabalhos relacionados ao tema estão voltados para a investigação do entendimento do mercado agropecuário brasileiro, sendo, em nível internacional, altamente competitivo. Esse é o caso dos estudos de Barbosa e Waquil (2001), Rubin e Rondinel (2004), Souza (2004), Bonjour, Figueiredo e Campos (2004), Pires, Gomes e Alves (2004) e Freitas, Fossati e Nicola (2005), entre outros.

Diante desse cenário, o objetivo geral do estudo é analisar a competitividade do agronegócio brasileiro, tendo como objetivos específicos: a) avaliar a competitividade internacional das commodities brasileiras negociadas na BM\&F, no período de 2003 a 2013 e b) verificar as exportações brasileiras por blocos econômicos.

${ }^{3}$ Commodities são produtos que funcionam como matéria-prima, produzidos em escala e que podem ser estocados sem perda de qualidade, como petróleo, suco de laranja congelado, boi gordo, café, soja e ouro. Commodity vem do inglês e originalmente tem significado de mercadoria. 
A elaboração desse artigo é de fundamental relevância, pois acredita-se que a avaliação do desempenho da competitividade internacional de cada commodity, ao longo de uma série histórica, seja importante para diagnosticar como tem evoluído o mercado agropecuário brasileiro vis-à-vis o mercado mundial.

\section{DESEMPENHO DA PRODUÇÃO DAS COMMODITES BRASILEIRAS}

\section{A Commodity Açúcar}

O Brasil é um dos maiores produtores mundiais de cana-de-açúcar e sua produção vem crescendo significativamente ao longo da década, como mostra a Figura 1.

Figura 1 - Produção brasileira de cana-de-açúcar no período de 2003 a 2013

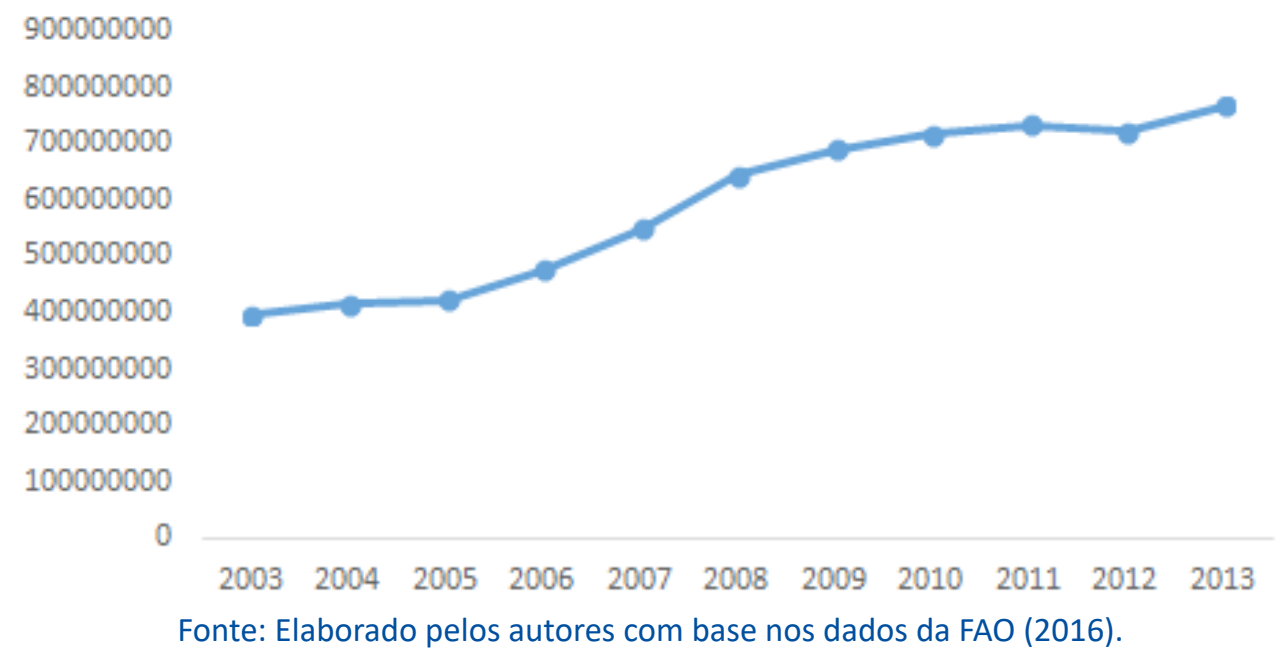

A produção de cana-de-açúcar do país em 2013 foi recorde e alcançou 768.090.444 toneladas, numa área colhida de 10.195.166 hectares, indicando um rendimento médio de $75.339 \mathrm{~kg} / \mathrm{ha}$. O crescimento da produção foi de 6,5\%, quando comparado ao ano anterior (IBGE, 2013).

Dessa forma, a participação do Brasil na produção mundial de cana-de-açúcar passou de 28,72\% em 2003 para 40,32\% em 2013. As exportações brasileiras também vêm crescendo de forma significativamente ao longo da década de 2000. Segundo Burnquist, Silveira e Rodrigues (2004) vários fatores vêm contribuindo de forma direta ou indireta para essa situação, entre eles o desenvolvimento da capacidade exportadora seguido pelo afastamento do governo do controle das cotas de exportação de açúcar e das estruturas portuárias; as dificuldades de aceso ao crédito no mercado nacional, o que pode ter estimulado a expansão das exportações; a reestruturação adotada pelo setor sucroalcooleiro, favorecendo uma maior porção de cana para a produção de açúcar e, além disso, deve-se levar em conta o estímulo nas exportações originado por uma desvalorização cambial.

\section{A Commodity Algodão}

A cotonicultura brasileira evoluiu acentuadamente nos últimos anos, posicionando o Brasil entre os cinco maiores exportadores mundiais de algodão. 
Figura 2 - Produção brasileira de algodão no período de 2003 a 2013

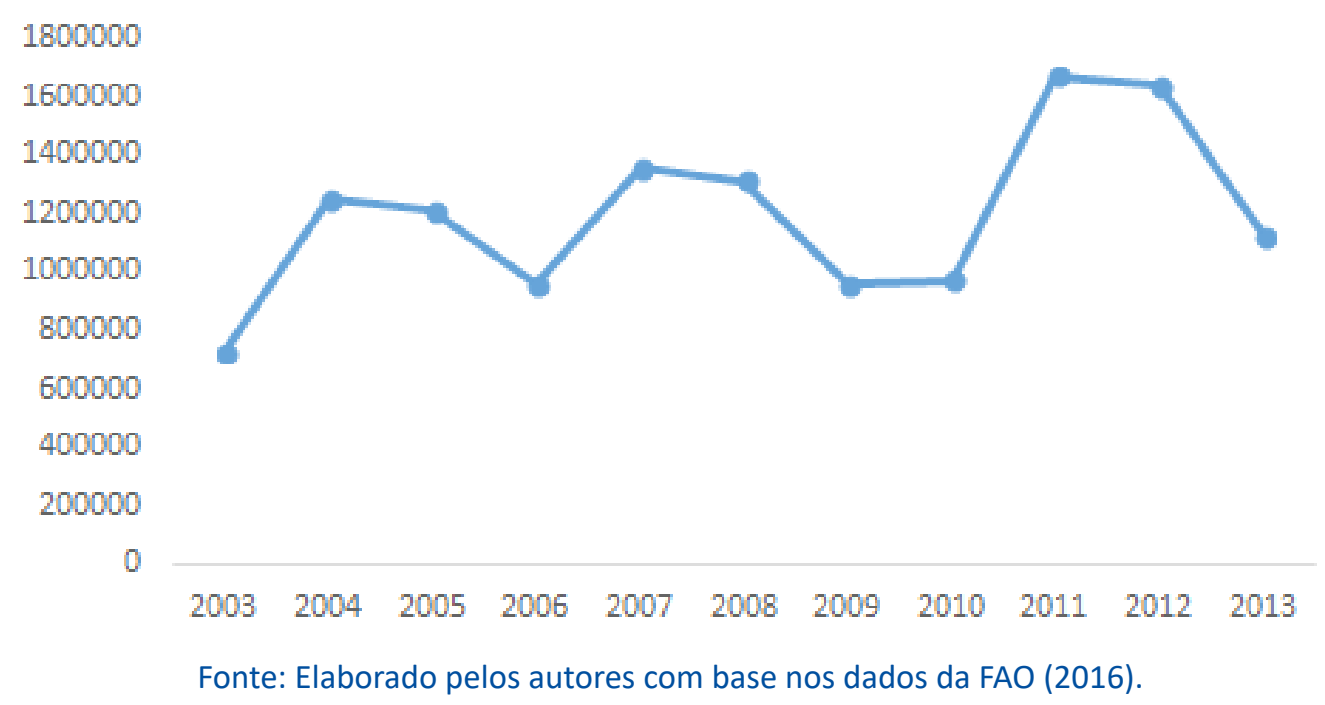

Novas técnicas de gerenciamento do campo, investimento, pesquisa e melhor beneficiamento aumentaram a qualidade e a quantidade do algodão brasileiro, adequando-o às necessidades das indústrias. Além do aumento da produção, a alta produtividade permitiu que o país destinasse uma fatia considerável de sua produção para o mercado externo, exportando algodão principalmente para Cazaquistão, Indonésia e Coreia do Sul. Nota-se, contudo, na Figura, 2 que a evolução do algodão ocorre de forma sutil, apresentando oscilações durante o período de análise, mas com tendência de crescimento.

O ano de 2013 repetiu o cenário internacional observado em 2012: estoques mundiais de pluma elevados e retração do consumo do algodão, deflagrado pela crise de crédito no final de 2008, resultando, assim, em preços depreciados. Em contrapartida, os preços das commodities concorrentes, como a soja e o milho, estiveram mais rentáveis, fazendo com que muitos cotonicultores optassem por estas em detrimento do algodão, causando uma redução de $31,7 \%$ na área colhida, que saiu de 1.381 .919 hectares em 2012 para 943.742 hectares em 2013. Como consequência, a produção nacional decresceu 31,2\%, ficando em 3.417.196 toneladas.

Além disso, em 2013 o Brasil foi surpreendido pela presença de uma nova praga quarentenária no país: a Helicoverpa armigera. Com pouco conhecimento sobre a praga e a inexistência de agrotóxico registrado no país para seu controle, os cotonicultores nacionais ficaram à mercê de medidas emergenciais aplicadas pelos órgãos competentes. Como agravante, o país passou por duas grandes estiagens que favoreceram a multiplicação e dispersão da $H$. armigera. Outra praga, já conhecida pelos cotonicultores, o bicudo do algodoeiro, também foi responsável por grandes ataques às lavouras. Esses fatos fizeram os custos de produção aumentarem, em ano de baixo preço do produto no mercado. Em virtude dos problemas relatados, aliados à redução da área plantada, a Bahia viu sua produção de algodão reduzir-se a 924.981 toneladas, 26,4\% menor quando comparado com 2012 (IBGE, 2013). 


\section{A commodity café}

Embora 2013 tenha sido um ano de safra baixa, considerando-se a bienalidade na produção, principalmente da espécie arábica, predominante no país, a safra brasileira de café alcançou 2.964.538 toneladas, indicando queda de 2,4\% em relação a 2012 (Figura 3). Práticas agrícolas cada vez mais usadas, como adensamento das plantas, "estresse hídrico", irrigação e podas bem conduzidas, têm colaborado para minimizar a variação entre safras, fazendo com que, cada vez mais, diminuam as diferenças entre anos de altas e baixas produtividades (IBGE, 2013).

Figura 3 - Produção brasileira de café no período de 2003 a 2013

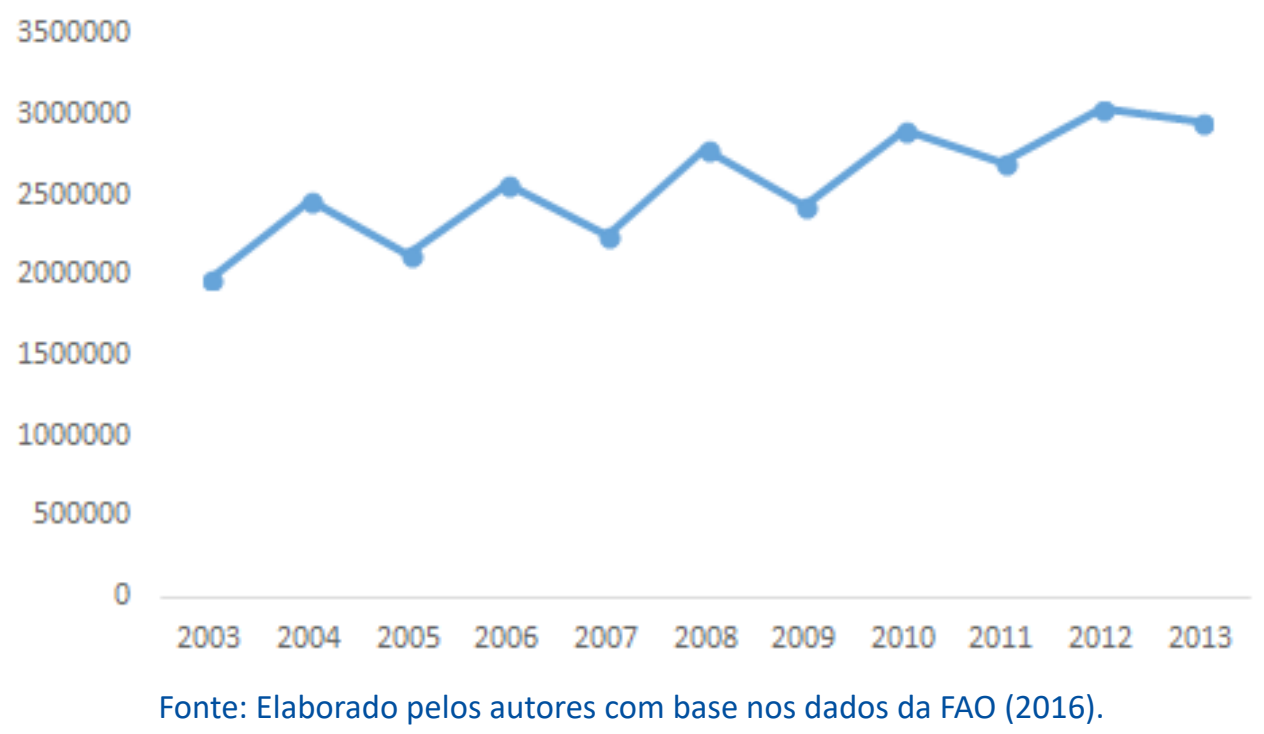

De acordo com Brito e Leite (2004) apud Freitas, Fossati e Nicola (2005), o agronegócio brasileiro de café é considerado competitivo apesar dos vários choques negativos sofridos, entre os quais pode-se citar fatores ambientais contrários ao bom andamento da safra, o que acaba por afetar a oferta da commodity, como o tabelamento de preços no mercado interno e o baixo preço do produto entre 2011 e 2013, ocasionado pelo aumento da oferta a um nível que a demanda não conseguiu acompanhar.

\section{A Commodity Carne Bovina}

A cadeia produtiva brasileira da carne bovina movimenta cerca de $\mathrm{R} \$ 167,5 \mathrm{bi}$ Ihões por ano, gerando aproximadamente 7 milhões de empregos. 0 setor produz 9,5 milhões de toneladas de carne, das quais 7,6 milhões são destinadas ao mercado interno e 1,8 milhão exportada para mais de 140 países (MAPA, 2017).

Assim entendido, o Brasil é um dos maiores exportadores de carne bovina, no entanto enfrenta dificuldades para exportar este produto em larga escala para mercados que pagam melhor remuneração, tais como a União Europeia e os Estados Unidos. Este fato deve-se à grande exigência desses países quanto à qualidade da carne, sanidade e rastreabilidade, sendo esses fatores deficientes na carne brasileira (MAIA FILHO et al., 2015). 
Figura 4 - Produção brasileira de carne bovina no período de 2003 a 2013

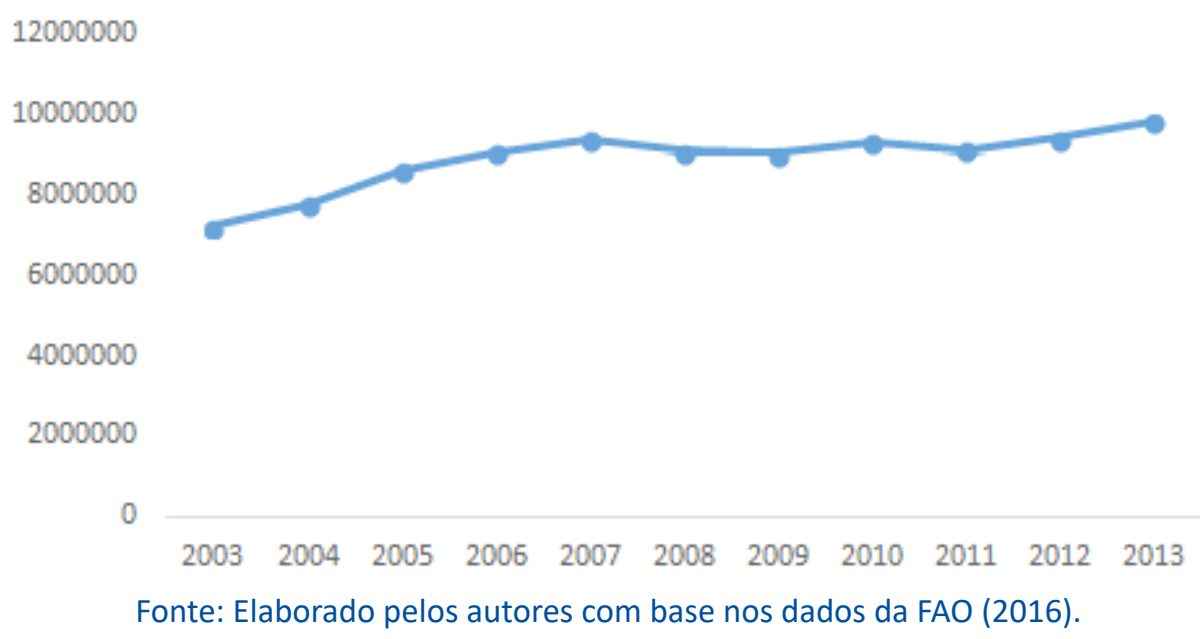

\section{A Commodity Milho}

A Figura 5 mostra a evolução da produção brasileira de milho no período compreendido entre 2003 e 2013. Ao longo da série histórica dos dados, observa-se que a produção de milho apresenta tendência crescente, com leves altas em alguns períodos. Segundo o relatório do IBGE (2013), a produção brasileira de milho em 2013 alcançou um recorde de 80.273.172 toneladas, um incremento de 12,9\% em relação a 2012.

Figura 5 - Produção brasileira de milho no período de 2003 a 2013

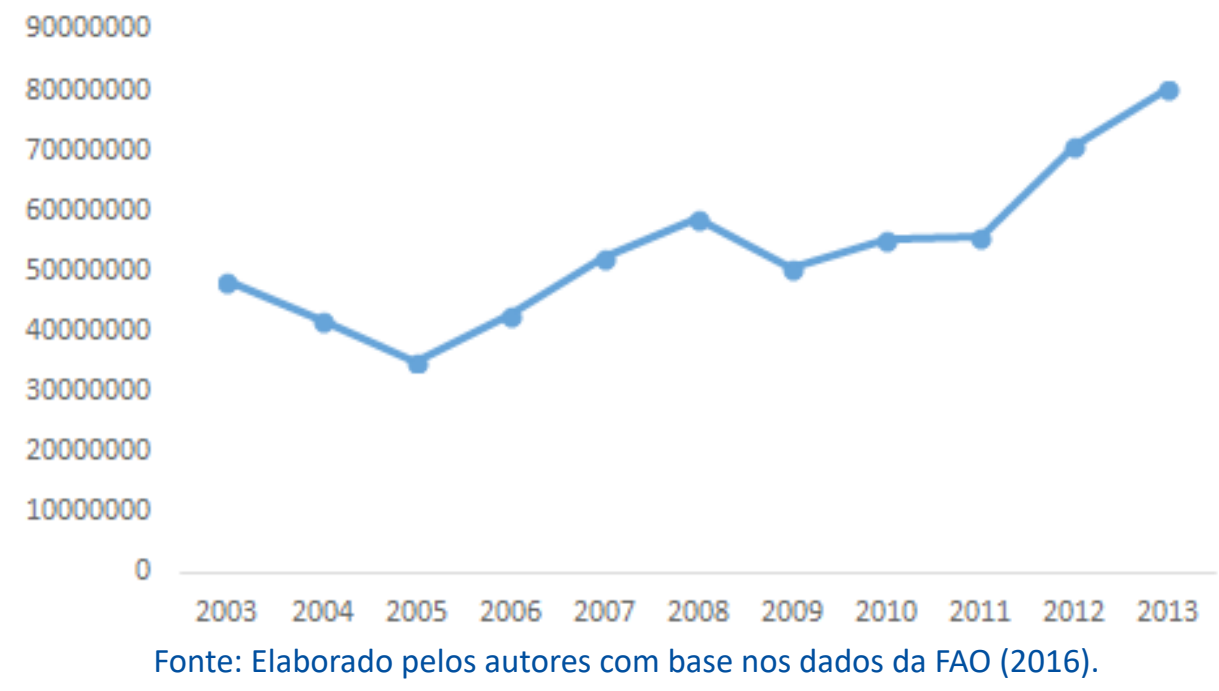

Os preços convidativos, principalmente na época de decisão de plantio da $2^{\mathrm{a}}$ safra, estimularam o aumento de área plantada, notadamente na Região Centro-Oeste. Em Mato Grosso, o clima mais chuvoso no outono também proporcionou aumento no rendimento médio, contribuindo para esse Estado registrar uma supersafra do cereal, ultrapassando o Paraná e tornando-se o maior produtor nacional. 


\section{A commodity soja}

A produção de soja está entre as atividades econômicas que, nas últimas décadas, apresentaram maior crescimento. Isso pode ser atribuído a diversos fatores, entre os quais: desenvolvimento e estruturação de um sólido mercado internacional relacionado com o comércio de produtos do complexo agroindustrial da soja; consolidação da oleaginosa como importante fonte de proteína vegetal, especialmente para atender demandas crescentes dos setores ligados à produção de produtos de origem animal; geração e oferta de tecnologias, que viabilizaram a expansão da exportação para diversas regiões do mundo (HIRAKURI; LAZZAROTTO, 2014).

O Brasil é segundo maior produtor mundial de soja, somente perdendo para os Estados Unidos, e, na última década vem aumentando consideravelmente sua produção, como mostra a Figura 6 . Atualmente a soja corresponde a 52,9\% da área total de grãos do país. O seu cultivo está concentrado nas regiões Sul e Centro-Oeste, que abrigam os cinco maiores produtores nacionais da cultura, Mato Grosso, Paraná, Rio Grande do Sul, Goiás e Mato Grosso do Sul.

Em 2003 a produção era cerca de 52 milhões de toneladas e passou em 2013 para 81 milhões aproximadamente $21,80 \%$ de taxa de crescimento. Entre alguns fatores que elevaram a produção estão o estímulo do mercado internacional e a possibilidade de uma mecanização total, tanto no plantio quanto na colheita.

Figura 6 - Produção brasileira de soja no período de 2003 a 2013

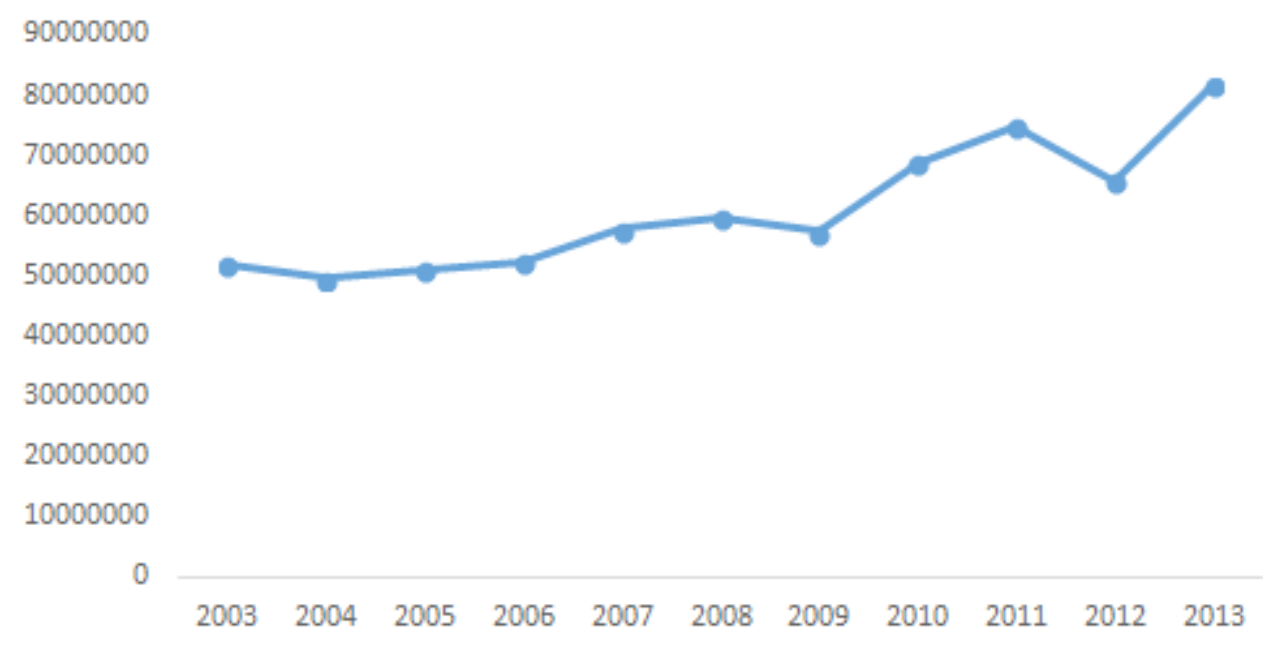

Fonte: Elaborado pelos autores com base nos dados da FAO (2016).

Na safra 2011/2012 houve redução da produtividade devido às adversas condições climáticas provocadas pelo "La Niña" e pela seca. A estiagem atingiu principalmente o Rio Grande do Sul, com perdas na produção por volta de 43\%, o Paraná com perda de $29 \%$, e o Mato Grosso do Sul com perda de $10 \%$. Nos demais Estados da região Centro Oeste as condições climáticas foram favoráveis para o aumento da produção (CONAB, 2012). 


\section{Participação das Commodites Brasileiras na Produção Mundial}

A Figura 7 mostra a participação percentual brasileira na produção de todas as commodities selecionadas no presente estudo. A commodity mais significativa é o açúcar, em que a produção nacional chega a representar quase $37 \%$ da produção total mundial do produto. $O$ café brasileiro também destaca-se perante a produção mundial e passa a representar cerca de $30 \%$ da produção mundial do setor. A soja brasileira também se destaca perante a produção mundial, atingindo seu pico em 2013, quando passa a representar $29,39 \%$ da produção mundial. A carne bovina elevou sutilmente sua participação ao longo da série, representando atualmente $15 \%$ da produção mundial do produto. A participação na produção mundial de milho se concentrou em torno de $7 \%$ nos dois últimos anos da série analisada, mostrando estabilidade produtiva. 0 algodão, por sua vez, não se mostra muito representativo na produção mundial, sendo responsável por cerca de $5 \%$.

Figura 7 - Participação percentual brasileira na produção mundial, commodities selecionadas, no período de 2003 a 2013

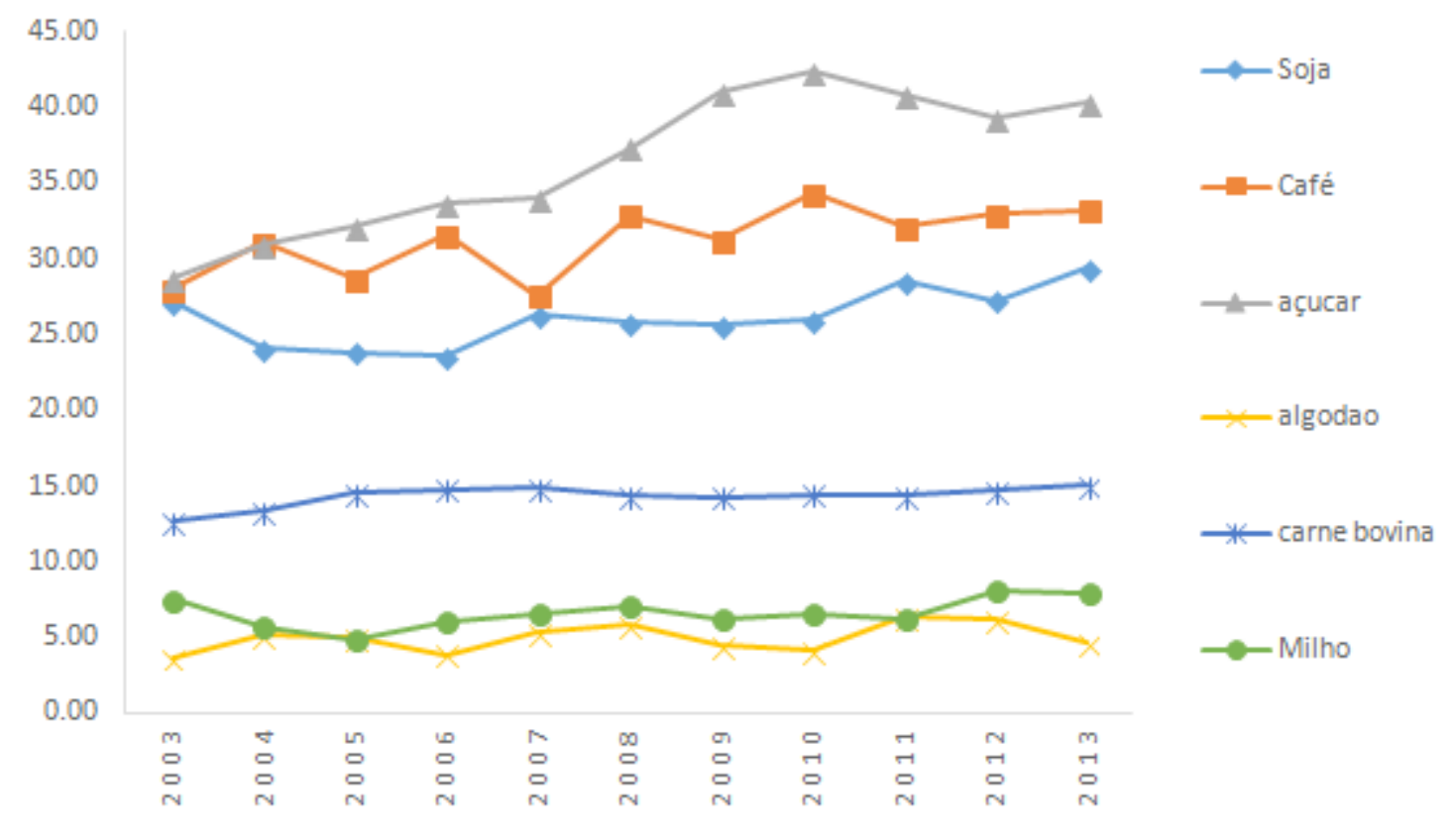

Fonte: Elaborado pelo autor com base nos dados da FAO (2016).

\section{METODOLOGIA}

Para mensurar a competitividade brasileira no comércio exterior das commodities selecionadas, optou-se pelo cálculo do índice da Vantagem Comparativa Revelada (VCR), do índice da Vantagem Comparativa Revelada Simétrica (VCRS), do Índice da Vantagem Relativa na Exportação (VRE), do Índice Competitividade Revelada (CR), do Indicador de Contribuição ao Saldo Comercial (ICSC), do Índice de Concentração por Produtos das Exportações (ICP), do Índice de Concentração por País de Destino (ICD) e da Taxa de Cobertura (TC). A seguir procura-se apresentar as expressões relativas a cada um desses índices. 


\section{Dados}

Os dados do estudo foram coletados de órgãos oficiais como a FAO, Instituto de Pesquisa Econômica (Ipeadata), Ministério da Indústria, Comércio Exterior e Serviços (MDIC) e Aliceweb. A descrição de cada variável foi feita da seguinte forma: como não está disponível a informação para o caso do boi gordo, que é negociado na BM\&F em número de arroba, foi construída uma proxy usando a carne bovina, sendo um somatório de todos os tipos de carne comercializadas no mercado, tais como: carne com osso, desossada, entre outras. No caso do café (em grão), foi usado café verde só por falta dos dados relacionados a essa commodity. Para as demais commodities não houve nenhuma alteração nos dados, nem no tipo de produto usado para a análise. O período analisado foi até o ano de 2013 devido à disponibilidade dos dados da FAO.

\section{Indicadores de Estrutura}

O índice de Vantagem Comparativa Revelada (VCR) mostra a vantagem que um país possui na produção de determinada commodity em relação ao resto do mundo. Seguindo Balassa (1965), a equação do VCR é dada por:

$$
\mathrm{VCR}_{\mathbf{j}}=\left[\frac{x_{i j}}{x_{i}}\right] /\left[\frac{x_{w j}}{x_{w}}\right]
$$

No presente trabalho, $X_{i j}$ é valor das exportações brasileiras do produto j; $X_{i}$ é valor total das exportações brasileiras; $X_{w j}$ é valor das exportações mundiais do produto j e $X_{w}$ o valor total das exportações mundiais.

O índice VCR é uma razão de valores proporcionais obtidos por meio da divisão das exportações brasileiras do produto j em relação ao total das exportações brasileiras pela exportação mundial do produto j em relação ao total mundial exportado. Dessa forma, seu resultado revela se o Brasil apresenta vantagem comparativa na pauta mundial de exportação de determinada commodity, ao comparar seu peso no comércio exportador mundial (FREITAS; FOSSATI; NICOLA 2005). Se o índice for maior do que 1, indica que o país em questão possui vantagem comparativa na exportação da commodity analisada; se o índice for inferior a 1, o país possui desvantagem comparativa revelada na exportação do produto.

A vantagem comparativa revelada de Balassa detém a limitação de que a desvantagem e a vantagem comparativa possuem dimensão assimétrica. A primeira varia entre 0 e 1, e a segunda, entre 1 e infinito (HIDALGO, 2005). A fim de superar essa limitação, Laursen (1998) desenvolveu um índice normalizando a expressão da seguinte forma:

$$
V C R S_{i j}=\frac{\left(V C R_{i j}-1\right)}{\left(V C R_{i j}+1\right)}
$$

O índice varia entre -1 e 1. Se o valor do índice $\mathrm{VCS}_{\mathrm{ij}}$ se encontrar no intervalo entre 0 e 1, dizem que esse país j possui vantagem comparativa revelada no produto i. Se os valores do índice $\mathrm{VCS}_{\mathrm{ij}}$ se encontram no intervalo entre -1 e 0 indicam que esse país não possui vantagem comparativa revelada no produto $\mathrm{i}$.

Outro índice pode ser utilizado para analisar o desempenho de um país na exportação de determinada commodity como o índice de Vantagem Relativa na Exportação (VRE), sendo calculado por meio da seguinte forma: 


$$
\mathrm{VRE}_{\mathrm{ki}}=\ln \left[\frac{x_{k i}}{x_{k r}} / \frac{x_{m i}}{x_{m r}}\right]
$$

onde, $X_{k i}$ são exportações brasileiras do produto $\mathrm{k} ; X_{k r}$ são as exportações mundiais do produto k excluindo o total de exportações brasileiras; $X_{m i}$ é o total das exportações brasileiras excluindo as exportações brasileiras do produto $\mathrm{k}$ e $X_{m r}$ é o total das exportações mundiais excluindo as exportações mundiais do produto $k$ e o total de exportações brasileiras.

Se o coeficiente for maior que 0 , o país possui vantagem relativa na exportação mundial do produto k; se o índice proporcionar um resultado negativo significa que o país apresenta uma desvantagem relativa na exportação mundial da commodity. Ressalta-se que, caso o valor obtido seja igual a 0 , significa que a participação do produto $\mathrm{k}$ no total das exportações do país analisado é idêntica à observada nas exportações mundiais, caracterizando uma situação neutra, quando o país não apresenta nem vantagem nem desvantagem na exportação.

Outro indicador consolidado na literatura é o de Competitividade Revelada (CR), que é o mais abrangente, visto que engloba tanto as exportações como as importações, apresentando o volume de comércio do país em relação a uma commodity específica. $O$ índice CR é apresentado da seguinte maneira:

$$
\mathrm{CR}_{\mathrm{ki}}=\ln \left[\begin{array}{l}
\frac{x_{k i}}{X_{k r}} / x_{m i} \\
\frac{x_{m i}}{M_{k i}} / M_{m i} \\
M_{k r} / M_{m r}
\end{array}\right]
$$

onde, $X_{k i}$ são as exportações brasileiras do produto k; $X_{k r}$ são as exportações mundiais do produto k excluindo o total de exportações brasileiras; $X_{m i}$ é o total das exportações brasileiras excluindo as exportações brasileiras do produto k; $X_{m r}$ é o total das exportações mundiais excluindo as exportações mundiais do produto $\mathrm{k}$ e o total de exportações brasileiras; $M_{k i}$ é a importação brasileira do produto k; $M_{k r}$ é a importação mundial do produto k excluindo o total de importações brasileiras; $M_{m i}$ é o total das importações brasileiras excluindo as importações brasileiras de k e $M_{m r}$ é o total das importações mundiais excluindo as importações mundiais do produto $k$ e o total de importações brasileiras.

Se o resultado do cálculo for maior que 0 , o país apresenta-se competitivo no comércio internacional; se o valor obtido for menor que 0 apresenta desvantagem, e caso for igual a 0 , o país encontra-se em igualdade de competitividade com o comércio mundial de determinada commodity.

Outra maneira de analisar vantagem comparativa é pelo Indicador de Contribuição ao Saldo Comercial (ICSC), desenvolvido por Lafay (1990). Diferentemente, contudo, dos indicadores de vantagens comparativas reveladas, esse indicador leva em consideração as importações. O ICSC tem a seguinte forma:

$$
I C S C_{i j}=\frac{100}{(X+M) / 2}\left[\left(X_{i}-M_{i}\right)-(X-M) \frac{\left(X_{i}+M_{i}\right)}{(X+M)}\right]
$$

em que $X i$ representa as exportações do setor $i$ efetuadas pelo País; e Mi se refere às importações deste mesmo setor; já $X$ e $M$, são respectivamente as exportações e importações totais do Brasil. Se $I C S C_{i j}$ for positivo, o produto i apresenta vantagem comparativa revelada e, por outro lado, se ICSC $_{i j}$ for negativo, o produto não apresenta vantagem comparativa revelada. 
O índice de concentração por produto das exportações (ICP), também conhecido como coeficiente Gini-Hirchman, quantifica a concentração das exportações de cada produto $i$ realizados pelo pais $j$ (Brasil). O ICP é representado pela seguinte equação:

$$
I C P_{i j}=\sqrt{\sum_{i}\left(\frac{X_{i j}}{X_{j}}\right)^{2}}
$$

Em que $X i j$ representa as exportações do produto $i$ pelo país $j$ (Brasil) e $X j$ representa as exportações totais do país $j$ (Brasil). O ICP varia no intervalo $[0,1]$. Quanto mais próximo a 1, mais concentradas serão as exportações em poucos produtos e, por outro lado, quanto mais próximo de 0 , mais diversificada será a composição da pauta de exportações.

O Índice de Concentração por Países de Destino (ICD) é um índice que mede o nível de concentração das exportações entre os países importadores. De acordo com Love (1979), esse índice é calculado da seguinte forma:

$$
I C D_{i j}=\sqrt{\sum_{j}\left(\frac{X_{i j}}{X_{i}}\right)^{2}}
$$

Onde $X_{i j}$ são as exportações do país i para o país $j, X_{i}$ são as exportações totais do país j. Um índice ICD elevado significa que um número pequeno de países tem uma importância muito grande na sua pauta de exportações. Por outro lado, um ICD baixo significa uma participação mais equilibrada dos diversos mercados.

Outro indicador mensurado é a taxa de cobertura das importações, que indica quantas vezes o volume das exportações do produto $i$ está cobrindo seu volume de importação. $O$ índice é obtido por meio da seguinte expressão:

$$
T C_{i j}=\frac{X_{i j} / M_{i j}}{X_{i} / M_{i}}
$$

Em que $X_{i j}$ e $M_{i j}$ são, respectivamente, as exportações e importações do setor $i$ do país $j$ (Brasil). Um valor superior a 1 traduz uma taxa de cobertura por produto superior à taxa de cobertura global, evidenciando tratar-se de um produto competitivo. Se o indicador for inferior a 1, significa que o produto não é competitivo na medida em que a sua taxa de cobertura é inferior à taxa de cobertura global.

\section{ANÁLISE DOS RESULTADOS}

O Brasil historicamente sempre se destacou no cenário internacional como um dos mais importantes produtores de algumas commodities como: o suco de laranja, o café, a soja, entre outros. Em anos mais recentes, no entanto, verifica-se que o país vem conseguindo, para algumas commodities, como boi gordo, soja, açúcar, aumentar a sua competitividade internacional. Isso tem permitido ao Brasil elevar a sua participação relativa no mercado, tornando-se. inclusive, o segundo maior produtor e exportador de carne e de soja, e o maior exportador mundial de açúcar. 


\section{Vantagem Comparativa Revelada (VCR)}

A Tabela 1 apresenta os cálculos do VCR para cada uma das commodities ao longo do período analisado. Como pode-se observar, houve com relação à carne bovina um salto qualitativo do índice, especialmente a partir de 2003 , em que passa de 7,30 para 11,83 em 2007. Pode-se dizer que são vários fatores apontados na literatura que contribuíram para que o Brasil galgasse essa posição de destaque no comércio internacional. Segundo Reis et al. (2004) e Souza (2004) apud Torres Jr. (2003), os fatores que mais têm contribuído são: pastagem natural, proporcionando menores custos de produção, o que consequentemente acarreta maior competitividade do produto no mercado internacional; a desvalorização do câmbio; o aumento da sanidade do rebanho bovino nacional; o cenário internacional favorável, os problemas sanitários nos rebanhos da Europa e da Argentina. Além desses, pode-se citar, também, o melhoramento genético do rebanho bovino, as melhorias nos canais de distribuição, expansão da área produtiva no Brasil e erradicação da febre aftosa em praticamente todo o território nacional.

Tabela 1 - Vantagem Comparativa Revelada (VCR) das commodities agropecuárias negociadas na BM\&F, no período 2003 a 2013

\begin{tabular}{ccccccc}
\hline Ano & Carne Bovina & Café verde & Algodão & Milho & Soja & Açúcar \\
\hline $\mathbf{2 0 0 3}$ & 7,30 & 23,47 & 2,27 & 3,46 & 28,33 & 14,74 \\
$\mathbf{2 0 0 4}$ & 10,16 & 23,06 & 3,63 & 4,82 & 30,67 & 14,73 \\
$\mathbf{2 0 0 5}$ & 10,22 & 22,62 & 3,92 & 0,94 & 29,62 & 16,99 \\
$\mathbf{2 0 0 6}$ & 11,68 & 22,17 & 2,60 & 2,01 & 30,94 & 20,41 \\
$\mathbf{2 0 0 7}$ & 11,83 & 21,63 & 3,86 & 6,20 & 25,46 & 17,28 \\
$\mathbf{2 0 0 8}$ & 10,48 & 20,32 & 5,79 & 5,77 & 27,58 & 16,39 \\
$\mathbf{2 0 0 9}$ & 8,83 & 21,45 & 6,23 & 4,66 & 28,27 & 22,55 \\
$\mathbf{2 0 1 0}$ & 9,44 & 21,86 & 4,35 & 4,96 & 23,14 & 24,36 \\
$\mathbf{2 0 1 1}$ & 8,37 & 21,06 & 5,45 & 5,74 & 26,40 & 22,50 \\
$\mathbf{2 0 1 2}$ & 9,39 & 18,05 & 8,08 & 11,49 & 24,57 & 20,96 \\
$\mathbf{2 0 1 3}$ & 10,91 & 18,79 & 4,64 & 14,02 & 30,93 & 20,78 \\
\hline
\end{tabular}

Fonte: Elaborado pelos es com base nos dados da FAO (2016).

A partir de 2008, porém, esse índice caiu de 10,48 para 9,39 em 2012 devido aos diferentes efeitos da crise ocorrida no período (2008-2013).

Outro produto brasileiro que vem se destacando no cenário internacional é o algodão. Em meados da década de 2000 observa-se uma substancial elevação do índice $\operatorname{VCR}(2,27$ em 2003), que atinge 8,08 no ano de 2012 , o maior valor da série estudada, mas caiu até 4,64 em 2013.

Em geral, a partir de 2003-2007, o VCR eleva-se substancialmente, como mostra a Tabela 1. Isso significa que a commodity em questão consegue aumentar sua competitividade perante o comércio mundial, porém começou a perder um pouco essa competitividade até 2013.

Com relação ao milho, nota-se que a partir de 2003 essa commodity aumenta sistematicamente a sua competitividade internacional, o VCR salta de 3,46 para 14,02, atingindo esse pico em 2013. As explicações dessa elevação brusca de competitividade, segundo Campos, Leite e Lima (2003), são: a desvalorização cambial que atingiu o país, 
um aumento da demanda internacional de milho devido principalmente à elevação do consumo de alimentos proteicos, tais como carnes, ovos e leite, e preço mais competitivo no mercado interno.

Em termos de competitividade internacional a partir de 2003, nenhuma commodity equipara-se à soja. A série apresentada na Tabela 1 revela que houve elevação significativa no período de análise. Após quebra da safra de grãos norte-americana ocasionada por seca histórica, os preços, segundo o Centro de Estudos Avançados em Economia Aplicada (Cepea), atingiram os maiores níveis registrados desde 2006, destacando-se que em janeiro o indicador soja Paranaguá (INDICADOR, 2014) verificou média de $R \$$ 71,99 por saca de $60 \mathrm{~kg}$. Com efeito, obteve-se no Brasil uma safra recorde dessa cultura. Foram produzidas 81.724 .477 toneladas de soja, representando acréscimo de $24,1 \%$ em relação a 2012, e esse fato colocou a soja como a principal cultura. Essa produção foi realizada em uma área de 27.906 .675 hectares, o que representa $2.928 \mathrm{~kg} / \mathrm{ha}$.

Outra commodity importante e antiga na pauta de exportação brasileira é o café, que no transcorrer da década de 2000, no entanto, vem diminuindo sua competitividade no período analisado, como mostra a evolução do índice VCR. Segundo Pires, Gomes e Alves (2004), um dos grandes problemas da cafeicultura nacional é a intervenção indireta do Estado, a qual provoca distorções no mercado ampliando a variabilidade dos preços e da renda do setor; outros fatores que instabilizam o mercado estão ligados a mudanças bruscas na política econômica e na política monetária restritiva, como elevação nas taxas de juros e alterações na política fiscal.

Um produto significativo na pauta exportadora brasileira é açúcar. Essa commodity aumenta sistematicamente a sua competitividade internacional, o VCR salta de 14,74 para 20,78, atingindo o pico de 24,36 em 2010. Essa diminuição observada no período 2010-2013 deve-se aos efeitos das condições climáticas.

\section{Vantagem Comparativa Revelada Simétrica (VCRS)}

A Tabela 2 apresenta a vantagem comparativa revelada simétrica para cada uma das commodities ao longo do período analisado.

Tabela 2 - Vantagem Comparativa Relativa Simétrica (VCRS) das commodities agropecuárias negociadas na BM\&F, no período 2003 a 2013

\begin{tabular}{ccccccc}
\hline Ano & Carne Bovina & Café verde & Algodão & Milho & Soja & Açúcar \\
\hline $\mathbf{2 0 0 3}$ & 0,76 & 0,92 & 0,39 & 0,55 & 0,93 & 0,87 \\
$\mathbf{2 0 0 4}$ & 0,82 & 0,92 & 0,57 & 0,66 & 0,94 & 0,87 \\
$\mathbf{2 0 0 5}$ & 0,82 & 0,91 & 0,59 & $-0,03$ & 0,93 & 0,89 \\
$\mathbf{2 0 0 6}$ & 0,84 & 0,91 & 0,44 & 0,34 & 0,94 & 0,91 \\
$\mathbf{2 0 0 7}$ & 0,84 & 0,91 & 0,58 & 0,72 & 0,92 & 0,89 \\
$\mathbf{2 0 0 8}$ & 0,83 & 0,90 & 0,70 & 0,70 & 0,93 & 0,88 \\
$\mathbf{2 0 0 9}$ & 0,79 & 0,91 & 0,72 & 0,65 & 0,93 & 0,91 \\
$\mathbf{2 0 1 0}$ & 0,81 & 0,91 & 0,63 & 0,66 & 0,91 & 0,92 \\
$\mathbf{2 0 1 1}$ & 0,79 & 0,90 & 0,69 & 0,70 & 0,92 & 0,91 \\
$\mathbf{2 0 1 2}$ & 0,81 & 0,89 & 0,78 & 0,84 & 0,92 & 0,91 \\
$\mathbf{2 0 1 3}$ & 0,83 & 0,89 & 0,65 & 0,87 & 0,94 & 0,91 \\
\hline
\end{tabular}

Fonte: Elaborado pelos autores com base nos dados da FAO (2016). 
Como podemos constatar, os resultados dessa Tabela confirmam que os produtos com vantagem comparativa são o café verde, carne bovina, milho, soja e açúcar. No caso do milho, ele perdeu sua vantagem em 2005, quando apresentou um índice negativo, mas fora esse ano, ele apresenta um índice maior do que zero, uma volta à competitividade no restante do período analisado.

\section{Vantagem Relativa na Exportação (VRE)}

Outro indicador do fortalecimento do Brasil no cenário internacional relacionada exclusivamente às exportações agropecuárias é o índice Vantagem Relativa na Exportação (VRE), conforme mostra a Tabela 3.

A evolução do índice para a carne bovina tem se mostrado positivo ao longo do período analisado, reforçando os resultados do índice anterior em relação ao desempenho ascendente da competitividade do mercado brasileiro dessa commodity.

Outra commodity que vem se comportando de forma contrária à citada anteriormente é o algodão, que em 2003 começa a diminuir consideravelmente o índice, tornando-se negativo, reafirmando o decrescimento na produtividade e, consequentemente, na competitividade do setor algodoeiro no cenário internacional.

Tabela 3 - Vantagem Relativa na Exportação (VRE) das commodities agropecuárias negociadas na BM\&F, no período 2003 a 2013

\begin{tabular}{ccccccc}
\hline Ano & Carne Bovina & Café verde & Algodão & Milho & Soja & Açúcar \\
\hline $\mathbf{2 0 0 3}$ & 0,74 & 0,69 & $-1,21$ & $-0,47$ & 2,09 & 1,43 \\
$\mathbf{2 0 0 4}$ & 0,86 & 0,62 & $-0,81$ & $-0,41$ & 1,88 & 1,24 \\
$\mathbf{2 0 0 5}$ & 0,77 & 0,71 & $-1,02$ & $-2,33$ & 1,55 & 1,32 \\
$\mathbf{2 0 0 6}$ & 0,87 & 0,71 & $-1,47$ & $-1,04$ & 1,42 & 1,65 \\
$\mathbf{2 0 0 7}$ & 0,81 & 0,7 & $-1,22$ & 0,22 & 1,47 & 1,25 \\
$\mathbf{2 0 0 8}$ & 0,67 & 0,63 & $-1,21$ & $-0,44$ & 1,97 & 1,02 \\
$\mathbf{2 0 0 9}$ & 0,68 & 0,81 & $-0,95$ & $-0,2$ & 2,12 & 1,79 \\
$\mathbf{2 0 1 0}$ & 0,54 & 0,77 & $-1,11$ & $-0,01$ & 1,89 & 1,85 \\
$\mathbf{2 0 1 1}$ & 0,3 & 0,93 & $-0,73$ & $-0,14$ & 1,88 & 1,69 \\
$\mathbf{2 0 1 2}$ & 0,51 & 0,69 & $-0,34$ & 0,68 & 1,99 & 1,64 \\
$\mathbf{2 0 1 3}$ & 0,72 & 0,47 & $-0,97$ & 0,87 & 2,34 & 1,59 \\
\hline
\end{tabular}

Fonte: Elaborado pelos autores com base nos dados da FAO (2016).

Com relação ao milho, observa-se que o VRE melhorou consideravelmente, dado que no início do período apresentou valores negativos bem elevados, mas de $2012 \mathrm{em}$ diante o índice torna-se positivo. O que fica claro é que apesar de a produção do milho internamente não ter dado grandes saltos, conforme já visto, em termos internacionais o VRE mostrou que o Brasil expandiu a sua competitividade externa. Os resultados ascendentes desse índice nos dois últimos anos levam a concluir que o país reúne as condições para ser um importante exportador mundial de milho.

O açúcar também apresentou valores positivos para esse índice e vem aumentando progressivamente seus resultados no decorrer do período, com um pequeno decréscimo em 2010, proporcionado por problemas climáticos já citados anteriormente. Essa 
evolução positiva dos valores vem mostrar que o país tem um setor sucroalcooleiro desenvolvido e com forte competitividade internacional, tendo inclusive meios para elevar ainda mais participação relativa do Brasil no cenário internacional.

O VRE para o café também vem evoluindo de forma ascendente no período analisado e vem conseguindo de forma lenta e gradual ampliar a sua participação no comércio mundial.

A soja também é uma commodity que evoluiu o VRE, que desde o início da série histórica apresentada mostra resultados satisfatórios. No que tange à competitividade do setor no mercado internacional, o Brasil tem conseguido se manter entre os três maiores exportadores da commodity, o que alavanca ainda mais a credibilidade do setor no cenário mundial.

\section{Competitividade Revelada (CR)}

A CR, conforme mencionado na metodologia, é uma medida agregada da competitividade de uma commodity em todos os setores do comércio. Quando o resultado é positivo revela que o país, naquele ano específico, possui vantagem comparativa no comércio internacional do produto, significando que exportou mais do que importou o determinado bem. Esse é o caso, por exemplo, da soja, do café, do açúcar e da carne bovina, conforme se pode verificar na Tabela 4, que ao longo da série sempre apresentaram resultados positivos. Isso demonstra que o país exporta mais essas commodities do que importa.

Tabela 4 - Índice de Competitividade Revelada (CR) das commodities agropecuárias negociadas na BM\&F, no período 2003 a 2013

\begin{tabular}{ccccccc}
\hline Ano & Carne Bovina & Café verde & Algodão & Milho & Soja & Açúcar \\
\hline $\mathbf{2 0 0 3}$ & 2,08 & 11,9 & $-0,45$ & 0,81 & 2,05 & 4,75 \\
$\mathbf{2 0 0 4}$ & 2,39 & 12,45 & 0,03 & 1,91 & 3,37 & 4,63 \\
$\mathbf{2 0 0 5}$ & 2,45 & 9,93 & 1,47 & $-0,25$ & 3,39 & 5,07 \\
$\mathbf{2 0 0 6}$ & 3,03 & $14,1^{*}$ & 0,36 & 0,96 & 5,54 & 5,39 \\
$\mathbf{2 0 0 7}$ & 3,07 & $14,53^{*}$ & 0,9 & 2,15 & 4,89 & 5,53 \\
$\mathbf{2 0 0 8}$ & 3,31 & $15,06^{*}$ & 2,34 & 1,98 & 5,63 & 5,37 \\
$\mathbf{2 0 0 9}$ & 2,93 & $14,85^{*}$ & 3,27 & 1,78 & 5,43 & 5,72 \\
$\mathbf{2 0 1 0}$ & 3,06 & $15,36^{*}$ & 2,31 & 3,25 & 5,62 & 6,21 \\
$\mathbf{2 0 1 1}$ & 2,73 & $15,78^{*}$ & 1,24 & 2,78 & 6,88 & 5,98 \\
$\mathbf{2 0 1 2}$ & 2,66 & 12,77 & 5,32 & 3,35 & 4,67 & 5,79 \\
$\mathbf{2 0 1 3}$ & 3,06 & 10,48 & 3,48 & 3,75 & 5,34 & 5,86 \\
\hline
\end{tabular}

* Estimação das importações brasileiras a unidade.

Fonte: Elaborado pelos autores com base nos dados da FAO (2016).

No caso da soja, do açúcar e da carne bovina o índice vem evoluindo de forma ascendente, demonstrando elevação da competitividade internacional dessas commodities. Já no caso do milho o índice mostrou-se negativo em 2005, porém crescente no restante do período, mostrando em 2005 que o setor tem aumentado suas importações em proporções maiores que as exportações, diminuindo assim sua vantagem comparativa no comércio internacional de milho naquele ano. Mesma análise ocorre com algodão, cujo índice mostrou-se negativo apenas em 2003, revelando uma diminuição da sua vantagem comparativa no comércio internacional dessa commodity. 


\section{Indicador de Concentração ao Saldo Comercial (ICSC)}

De acordo com a Tabela 5, o índice de concentração ao saldo comercial para cada produto analisado é positivo, exceto para o algodão, que apresentou um índice negativo em 2003, porém depois os índices mostraram-se positivos, caracterizando uma trajetória de vantagens comparativas.

Tabela 5 - Indicador de concentração ao saldo comercial das commodities agropecuárias negociadas na BM\&F, no período 2003 a 2013

\begin{tabular}{ccccccc}
\hline $\begin{array}{c}\text { Produto } \\
\text { Anos }\end{array}$ & Soja & Café verde & Açúcar & Algodão & Carne bovina & Milho \\
\hline $\mathbf{2 0 0 3}$ & 5,24 & 1,72 & 2,99 & $-0,01$ & 2,57 & 2,05 \\
$\mathbf{2 0 0 4}$ & 5,29 & 1,75 & 2,8 & 0,16 & 1,86 & 0,54 \\
$\mathbf{2 0 0 5}$ & 4,23 & 2,03 & 3,29 & 0,31 & 1,85 & 0,03 \\
$\mathbf{2 0 0 6}$ & 3,97 & 2,06 & 4,51 & 0,13 & 2,13 & 0,25 \\
$\mathbf{2 0 0 7}$ & 4,09 & 2,07 & 3,23 & 0,21 & 2,07 & 1,07 \\
$\mathbf{2 0 0 8}$ & 6,68 & 2,08 & 2,86 & 0,32 & 1,96 & 0,63 \\
$\mathbf{2 0 0 9}$ & 7,4 & 2,45 & 5,55 & 0,43 & 1,88 & 0,73 \\
$\mathbf{2 0 1 0}$ & 6,41 & 2,56 & 6,39 & 0,37 & 1,83 & 1,05 \\
$\mathbf{2 0 1 1}$ & 7,00 & 3,12 & 5,89 & 0,46 & 1,53 & 0,99 \\
$\mathbf{2 0 1 2}$ & 7,04 & 2,36 & 5,27 & 0,86 & 1,73 & 2,15 \\
$\mathbf{2 0 1 3}$ & 9,37 & 1,89 & 4,94 & 0,44 & 2,10 & 2,54 \\
\hline
\end{tabular}

Fonte: Elaborado pelos autores com base nos dados da FAO (2016).

\section{Índice de Concentração por Produtos (ICP) e por Destino (ICD)}

São apresentados nas Tabelas 6 e 7 os resultados da concentração de produtos e mercados de destino, das medidas de vantagens comparativas e do tipo de comércio internacional do Brasil, além do valor e da taxa de crescimento das exportações. O fluxo do comércio exterior brasileiro com os grandes blocos econômicos registra de 2003 a 2013 oscilações e uma tendência de aumento percentual com alguns grandes agentes do comércio internacional, principalmente o Mercosul e a Ásia.

Tabela 6 - Exportações do Brasil por blocos econômicos entre 2003-2013 em (\%)

\begin{tabular}{cccccccccc}
\hline $\begin{array}{c}\text { Bloco } \\
\text { país }\end{array}$ & $\begin{array}{c}\text { União } \\
\text { Europeia }\end{array}$ & Nafta & Mercosul & $\begin{array}{c}\text { Ásia } \\
\text { (Exclusive } \\
\text { Oriente) }\end{array}$ & $\begin{array}{c}\text { Aladi } \\
\text { (exclusive } \\
\text { Mercosul) }\end{array}$ & África & Liga Árabe & Outros & Total \\
\hline $\mathbf{2 0 0 3}$ & 25,78 & 28,23 & 7,77 & 15,96 & 10,19 & 3,91 & 3,77 & 4,39 & 100,00 \\
$\mathbf{2 0 0 4}$ & 25,6 & 26,44 & 9,24 & 15,08 & 11,43 & 4,39 & 4,17 & 3,65 & 100,00 \\
$\mathbf{2 0 0 5}$ & 22,89 & 24,32 & 9,91 & 15,66 & 11,84 & 5,05 & 4,4 & 5,94 & 100,00 \\
$\mathbf{2 0 0 6}$ & 22,59 & 22,87 & 10,15 & 15,11 & 12,93 & 5,41 & 4,84 & 6,1 & 100,00 \\
$\mathbf{2 0 0 7}$ & 25,25 & 19,88 & 10,8 & 15,62 & 12,11 & 5,34 & 4,34 & 6,66 & 100,00 \\
$\mathbf{2 0 0 8}$ & 23,54 & 17,07 & 10,98 & 18,98 & 10,99 & 5,14 & 4,96 & 8,34 & 100,00 \\
$\mathbf{2 0 0 9}$ & 22,35 & 13,16 & 10,35 & 26,3 & 9,33 & 5,68 & 6,14 & 6,7 & 100,00 \\
$\mathbf{2 0 1 0}$ & 21,46 & 12,63 & 11,19 & 27,87 & 9,39 & 4,59 & 6,23 & 6,64 & 100,00 \\
$\mathbf{2 0 1 1}$ & 20,77 & 12,9 & 10,88 & 29,96 & 8,68 & 4,77 & 5,9 & 6,14 & 100,00 \\
$\mathbf{2 0 1 2}$ & 20,24 & 13,99 & 9,4 & 31,05 & 9,17 & 5,03 & 6,11 & 5,01 & 100,00 \\
$\mathbf{2 0 1 3}$ & 19,72 & 13,13 & 10,19 & 32,07 & 10,62 & 4,58 & 5,78 & 3,91 & 100,00 \\
\hline
\end{tabular}

Fonte: Elaborada pelos autores. Dados disponibilizados pelo MDIC/Secex, sistema Aliceweb. 
Em relação à evolução das exportações, constata-se para o Brasil crescimento ao longo do período analisado. Em 2013 o valor exportado atingiu 330,8\% em relação as exportações realizadas em 2003. Quanto ao grau de produtos, o ICP mostra ser significativo na diversificação de produtos na pauta das exportações. Nesse caso, o Brasil tem uma maior estabilidade nas receitas cambiais (Tabela 7).

Tabela 7 - Índice de concentração por produtos das exportações das commodities agropecuárias negociadas na BM\&F, no período 2003 a 2013

\begin{tabular}{ccccc}
\hline Índice & $\begin{array}{c}\text { Exportações (USS } \\
\text { 1000) }\end{array}$ & $\begin{array}{c}\text { Crescimento das } \\
\text { exportações base 2003 }\end{array}$ & ICP & ICD \\
\hline $\mathbf{2 0 0 3}$ & 73.203 .222 & 100,0 & 0,07 & 0,44 \\
$\mathbf{2 0 0 4}$ & 96.677 .498 & 132,1 & 0,07 & 0,43 \\
$\mathbf{2 0 0 5}$ & 118.529 .184 & 161,9 & 0,06 & 0,41 \\
$\mathbf{2 0 0 6}$ & 137.807 .469 & 188,3 & 0,07 & 0,40 \\
$\mathbf{2 0 0 7}$ & 160.649 .072 & 219,5 & 0,06 & 0,40 \\
$\mathbf{2 0 0 8}$ & 197.942 .442 & 270,4 & 0,08 & 0,40 \\
$\mathbf{2 0 0 9}$ & 152.994 .742 & 209,0 & 0,10 & 0,41 \\
$\mathbf{2 0 1 0}$ & 201.915 .285 & 275,8 & 0,10 & 0,41 \\
$\mathbf{2 0 1 1}$ & 256.039 .574 & 349,8 & 0,10 & 0,42 \\
$\mathbf{2 0 1 2}$ & 242.578 .013 & 331,4 & 0,10 & 0,43 \\
$\mathbf{2 0 1 3}$ & 242.178 .649 & 330,8 & 0,11 & 0,43 \\
\hline
\end{tabular}

Fonte: Elaborada pelos autores. Dados disponibilizados pelo MDIC/Secex, sistema Aliceweb.

De acordo com Love (1979), uma pauta de exportações mais diversificadas pode significar também indício de trocas mais estáveis. Segundo Hidalgo (2005), diversos fatores determinam o grau de diversificação das exportações: o nível de desenvolvimento econômico, que reflete estruturas de produção mais complexa; a proximidade a polos comerciais e o tamanho da economia. Uma economia pequena tem menos possibilidades de produzir, em grande escala, uma maior variedade de produtos, assim, apresentará um ICP maior. O ICD indicou uma participação mais equilibrada nos diversos mercados. Em tal circunstância, o Brasil estará menos sujeito às flutuações na receita de suas exportações.

\section{Taxa de Cobertura}

A Tabela 8 apresenta a taxa de cobertura das commodities analisadas. Os resultados que saem dessa tabela mostram que todas as commodities são competitivas, exceto o algodão, que apresentou uma taxa de cobertura igual a 0,97, menor que 1 no início do período (2003), mas que vem melhorando sua competitividade ao longo do período restante. 
Tabela 8 - Taxa de cobertura das commodities negociados na BM\&F no período 2003-2013

\begin{tabular}{ccccccc}
\hline TC & Soja & Café & Açúcar + & Algodão & $\begin{array}{c}\text { Carne } \\
\text { bovina+ }\end{array}$ & Milho \\
\hline $\mathbf{2 0 0 3}$ & 12,86 & 225780,01 & 194,85 & 0,97 & 13,34 & 3,68 \\
$\mathbf{2 0 0 4}$ & 49,97 & 398761,30 & 171,66 & 1,65 & 18,39 & 11,36 \\
$\mathbf{2 0 0 5}$ & 50,91 & 33639,11 & 282,05 & 7,15 & 19,88 & 1,34 \\
$\mathbf{2 0 0 6}$ & 398,91 & $-{ }^{*}$ & 359,82 & 2,24 & 32,76 & 3,93 \\
$\mathbf{2 0 0 7}$ & 179,21 & $-{ }^{*}$ & 347,96 & 3,22 & 29,00 & 11,36 \\
$\mathbf{2 0 0 8}$ & 305,36 & $-{ }^{*}$ & 237,55 & 11,69 & 30,32 & 8,65 \\
$\mathbf{2 0 0 9}$ & 262,09 & $-{ }^{*}$ & 350,98 & 30,51 & 22,33 & 7,00 \\
$\mathbf{2 0 1 0}$ & 275,31 & $-{ }^{*}$ & 498,32 & 10,75 & 22,47 & 26,17 \\
$\mathbf{2 0 1 1}$ & 1022,11 & $-{ }^{*}$ & 423,55 & 3,77 & 16,59 & 17,78 \\
$\mathbf{2 0 1 2}$ & 108,66 & 366996,67 & 330,01 & 215,48 & 14,77 & 30,24 \\
$\mathbf{2 0 1 3}$ & 185,45 & 34091,20 & 320,45 & 31,29 & 20,02 & 40,81 \\
\hline
\end{tabular}

O símbolo (-*) significa ausência de importações indiretamente da TC

Fonte: Elaborado pelos autores com base nos dados da FAO (2016).

\section{CONCLUSÃO}

O presente trabalho procurou analisar a competitividade das commodities brasileiras sob a ótica de indicadores de vantagens comparativas. Foram mensurados índices de vantagens comparativas reveladas, índices de concentração das exportações, por produtos e destinos, e identificado o desempenho dos produtos no comércio exterior.

Após a análise dos resultados percebe-se que o Brasil possui vantagem comparativa na produção e exportação de praticamente todas as commodities analisadas, com exceção do algodão, não obstante todos os seus valores mostraram-se ascendentes ao longo do período analisado.

O índice Vantagem Relativa na Exportação revelou que o país possui alta competitividade, desde o início do período estudado, na exportação de soja e açúcar. Já o milho vem melhorando seus índices a partir de 2012, demonstrando que pode se tornar um bom atrativo para o setor do agronegócio brasileiro. O café e a carne bovina apresentam pouca competitividade externa, mas vêm melhorando suas posições internacionalmente. Contrariamente, o algodão não apresenta um bom índice.

A análise do Índice Competitividade Revelada mostrou-se positiva em quase todas as commodities avaliadas, com exceção do algodão e do milho em alguns anos. Isso permitiu inferir que o Brasil, evidentemente, exporta mais café, carne bovina, soja e açúcar do que importa, o que leva o país a ter saldo positivo no mercado internacional desses produtos. Já as exportações de algodão e milho mostraram-se inferiores em alguns períodos, porém vêm crescendo no início dos anos da série.

Quanto aos demais índices, verificou-se vantagem comparativa do Brasil em praticamente todos os períodos e produtos analisados, além da sua diversificação. Dessa forma, políticas de apoio à modernização desses setores poderiam ser empregadas pelo governo para manter suas vantagens comparativas no comércio internacional e recuperar outros setores que, por algum motivo, possam mostrar-se fracos. 


\section{REFERÊNCIAS}

BALASSA, B. Trade Liberalization and Revealed Comparative Advantage. Manchester School of Economic and Social Studies, 33, p. 99-123, 1965.

BARBOSA, Alexandre, E.; WAQUIL, Paulo, D. O rumo das exportações agrícolas brasileiras frente as negociações para a formação da Área de Livre Comércio das Américas (Alca). Indicadores Econômicos FEE, Porto Alegre, vol. 29, n. 3, p. 70-85, nov. 2001.

BONJOUR, Sandra C. M.; FIGUEIREDO, Adriano M. R.; CAMPOS, Antônio C. Mudanças na preferência internacional da carne bovina e alterações nos preços e comércio exterior. CONGRESSO BRASILEIRO DE ECONOMIA E SOCIOLOGIA RURAL - DINÂMICA SETORIAIS E DESENVOLVIMENTO REGIONAL, 42., 2004, Cuiabá. Anais [...]. Cuiabá, MT, jul. 2004.

BRITO, Miller, R.; LEITE, Carlos, A. M. Análise fracional do mercado internacional do café. CONGRESSO BRASILEIRO DE ECONOMIA E SOCIOLOGIA RURAL - DINÂMICA SETORIAIS E DESENVOLVIMENTO REGIONAL, 42., 2004, Cuiabá. Anais [...]. Cuiabá, MT, jul. 2004.

BURNQUIST, Heloísa L.; SILVEIRA, Luciana T.; RODRIGUES, Francine R. Análise da exportação brasileira de açúcar e a paridade de preços doméstico e internacional. CONGRESSO BRASILEIRO DE ECONOMIA E SOCIOLOGIA RURAL - DINÂMICA SETORIAIS E DESENVOLVIMENTO REGIONAL, 42., Cuiabá. Anais [...]. Cuiabá, MT, jul. 2004.

CAMPOS, Silvia K.; LEITE, Sheila C. F.; LIMA, João E. Análise da oferta de milho no Brasil no período de 1982 a 2001. CONGRESSO BRASILEIRO DE ECONOMIA E SOCIOLOGIA RURAL - EXPORTAÇÕES, SEGURANÇA ALIMENTAR E INSTABILIDADE DE MERCADOS, 41., 2003, Juiz de Fora. Anais [...]. Juiz de Fora, MG, jul. 2003.

CONAB. Companhia Nacional de Abastecimento. Séries históricas de produção de grãos. 2012. Disponível em: https://www.conab.gov.br. Acesso em: 8 mar. 2017.

FAO. Food and Agriculture Organization of the United Nations. Available from: http://www.fao.org. Cited: dez. 2016.

FREITAS, C. A.; FOSSATI, D. M.; NICOLA, D. S. Avaliando a competitividade internacional das commodities brasileiras negociadas na BM\&F, no período de 1990-2003. In: CONGRESSO BRASILEIRO DE ECONOMIA E SOCIOLOGIA RURAL, 43., Instituições, Eficiência, Gestão e Contratos no Sistema Agroindustrial, 2005, Ribeirão Preto. Anais [...]. Ribeirão Preto, 2005.

HIDALGO, A. B. Inserção das regiões brasileiras no comércio internacional: os casos da Região Nordeste e do Estado de Pernambuco. Revista Ensaios FEE, Porto Alegre, v. 26, n. 2, p. 965-1.018, nov. 2005.

HIDALGO, A. B.; MATA, D. F. P. G. A especialização do Nordeste brasileiro e do Estado de Pernambuco no comércio exterior. Recife: Pimes; Departamento de Economia, 2003. 32p. (Texto para discussão, 465).

HIRAKURI, Marcelo Hiroshi; LAZZAROTTO, Joelsio José. O agronegócio da soja nos contextos mundial e brasileiro. Documentos Embrapa, Londrina, n. 349, 2014.

IBGE. Instituto Brasileiro de Geografia e Estatística. Produção Agrícola Municipal (PAM), culturas temporais e permanentes. Brasil: IBGE, 2013. Vol. 40.

INDICADOR soja: Paranaguá. Série de preços. Piracicaba: Escola Superior de Agricultura "Luiz de Queiroz" - Esalq, Centro de Estudos Avançados em Economia Aplicada - Cepea, 2014.

IPEA. Instituto de Pesquisa Econômica Aplicada. 2017. Disponível em: http://www.ipea.gov.br. Acesso em: jan. 2017.

LAFAY, G. La mesure des avantages comparatifs révélés - Exposé de La méthodologie du CEPII. Economie Prospective Internationale, Paris, FR: Centre d' Etudes Prospectives et d' Informations Internationales, v. 41, n. 1, p. 27-43, 1990.

LAURSEN, K. Revealad Comparative Advantage and the Alternatives as Measures of International Specialization. Working Paper, Copenhagen: Danish Rearch Unit for Dynamics, n. 98-30, 1998.

LOVE, J. Trade concentration and export instability. The Journal of Development Studies, v. 15, n. 3, p. 6069, 1979.

MAIA FILHO, Geraldo Helber Batista et al. Mercado consumidor e a qualidade de carne bovina no Brasil. Caderno de Ciências Agrárias, v. 7, n. Suppl, p. 191-204, 2015.

MAPA. Ministério de Agricultura, Pecuária e Abastecimento. 2017. Disponível em: http://www.agricultura.gov.br/. Acesso em: jan. 2018.

MDIC. Ministério da Indústria, Comércio Exterior e Serviços. Secretaria de Comércio Exterior (Secex). Disponível em: http://www.mdic.gov.br. Acesso em: jan. 2017. 
PAGANINI, Caio Cezar; FRAGA, Gilberto Joaquim. Padrão de especialização do comércio internacional do Paraná no Período 2001-2011. Revista Paranaense de Desenvolvimento-RPD, v. 35, n. 127, p. 135-154, 2014.

PIRES, Mônica, M.; GOMES, Marília, F. M.; ALVES, Jaênes, M. Fatores de crescimento das receitas das exportações brasileiras de café. CONGRESSO BRASILEIRO DE ECONOMIA E SOCIOLOGIA RURAL - DINÂMICA SETORIAIS E DESENVOLVIMENTO REGIONAL, 42., 2004, Cuiabá. Anais [...]. Cuiabá, MT, jul. 2004.

REIS, Janderson D. et al. Oferta brasileira de exportação de carne bovina, 1996-2002. CONGRESSO DA SOCIEDADE BRASILEIRA DE ECONOMIA E SOCIOLOGIA RURAL - DINÂMICAS SETORIAIS E DESENVOLVIMENTO REGIONAL, 42., 2004, Cuiabá. Anais (resumos) [...]. Cuiabá, MT, 25 a 28 de julho de 2004.

RUBIN, Luciane S.; RONDINEL, Ricardo. Vantagens comparativas e orientação das exportações: estudo do caso do café, do fumo e da soja no período de 1989-2001. Rila-Revista de Integração Latino-Americana, Santa Maria: UFSM, n. 1, ano 1, 2004.

SOUZA, Maurício J. P. Vantagem comparativa revelada e orientação regional de relevantes produtos do agronegócio brasileiro no período de 1992 a 2002. 2004. Monografia (Conclusão de curso de Graduação em Ciências Econômicas) - Universidade Federal de Santa Maria, Santa Maria, 2004.

TORRES JR., Alcides de M. et al. Pecuária de corte: mercados e perspectivas. Agroanalysis: a Revista de agronegócios da FGV, FGV, p. 8-11, out. 2003. 